\title{
Erratum to: Platelet-rich Plasma and Other Cellular Strategies in Orthopedic Surgery
}

\author{
Phillip N. Williams $^{1} \cdot$ George Moran $^{1} \cdot$ James P. Bradley $^{2} \cdot$ Neal S. ElAttrache $^{3}$ • \\ Joshua S. Dines ${ }^{1}$
}

Published online: 15 July 2017

(C) Springer Science+Business Media, LLC 2017

Erratum to: Curr Rev. Musculoskelet Med (2015) 8(1):32-39

DOI 10.1007/s12178-014-9246-7.

This article was previously published as a chapter entitled "Biologics and Patches" in the following book:

L.V. Gulotta and E.V. Craig (eds.), Massive Rotator Cuff Tears: Diagnosis and Management, DOI 10.1007/978-14899-7494-5_6, (C) Springer Science + Business Media New York 2015.

The online version of the original article can be found at http://dx.doi:10. 1007/s12178-014-9246-7

\section{Phillip N. Williams}

WilliamsP@HSS.EDU

James P. Bradley

bradleyjp@upmc.edu

Joshua S. Dines

dinesj@hss.edu

1 Division of Sports Medicine and Shoulder Surgery, Hospital for Special Surgery, 535 E 70th Street, New York, NY 10021, USA

2 Center for SportsMedicine, University of PittsburghMedical Center, 3200 Water Street, South Side, Pittsburgh, PA 15203, USA

3 Kerlan Jobe Orthopaedic Clinic, 6801 Park Terrace, Suite 1400, Los Angeles, CA 90045, USA 